\title{
Duas visões da intencionalidade coletiva: uma análise entre Michael Bratman e John Searle
}

\author{
Two views of collective intentionality: an analysis between \\ Michael Bratman and John Searle
}

\author{
Caio Motta \\ Graduação em andamento em Ciências Sociais (2014). Universidade Estadual Paulista Júlio de Mesquita \\ Filho - UNESP. Faculdade de Ciências e Letras de Araraquara (FCLAR). Araraquara, SP - Brasil.
}

\begin{abstract}
Resumo: Neste artigo, propõe-se uma comparação entre dois filósofos responsáveis por distintos conceitos de intencionalidade coletiva: Michael Bratman e John Searle. Tomamos como foco a teoria do primeiro autor (Bratman) e, a partir da exposição de sua teoria da intenção no caso individual, partimos para suas formulações acerca da intencionalidade coletiva. Durante a exposição, foi realizada a comparação com a teoria da intencionalidade coletiva de outro filósofo, John Searle, com o objetivo de ver as possíveis falhas e sucessos de ambas as teorias, além de sua mera diferença. No final, reduzimos ao absurdo as principais hipóteses de Searle e afirmamos que sua teoria, apesar de suas qualidades, contém falhas ausentes da teoria de Bratman.
\end{abstract}

Palavras-chave: Michael Bratman; John Searle; Intencionalidade Coletiva; Ação Coletiva; Intencionalidade.

\begin{abstract}
In this article, we propose a comparison between two philosopher's different concepts of collective intentionality: Michael Bratman and John Searle. We focus on the theory of the first author (Bratman) and, starting from the exposition of his theory of intention in the individual case, we move to an appraisal of his formulations about collective intentionality. Along the exposition, a comparison is made with the theory of collective intentionality of John Searle, in order to see the possible failures and successes of both theories, in addition to their mere difference. In the end, we reduce Searle's major hypothesis to an absurdity, asserting that his theory - despite its qualities - contains flaws which are absent from Bratman's theory.
\end{abstract}

Keywords: Michael Bratman; John Searle; Collective Intentionality; Collective Action; Intentionality. 


\section{Introdução}

Primeiramente, começaremos analisando a teoria da intenção desenvolvida por Michael Bratman em “Two Faces of Intention" (1984), depois nos deteremos em sua concepção de intenção coletiva ou agência compartilhada desenvolvida em outros artigos e livros, e a compararemos com a teoria da intencionalidade coletiva de Searle. Diferente de Searle (2002), que apresenta uma teoria da intencionalidade em que a intenção é apenas um tipo de intencionalidade, Bratman foca, em sua análise, apenas na intenção e sua natureza ontológica, não analisando outros tipos de intencionalidade como desejo, crenças, esperar, acreditar, etc. No final do desenvolvimento, depois de compararmos as duas teorias, apresentaremos argumentos que contestam a efetividade da teoria de Searle.

\section{Desenvolvimento}

De forma semelhante a Searle (2001), Bratman preocupou-se com a formulação de uma explicação adequada da causação mental e sua função na correspondência entre estado mental ou psicológico e conteúdo representacional, contida na fórmula de Searle "S(p)", em que "S" é o estado mental e " $\mathrm{p}$ " o conteúdo representacional. Para Searle (2002), a característica central da intencionalidade é o fato dela ser uma capacidade mental de representar objetos e estados de coisas no mundo, expressando-se através de relações causais entre dois níveis: o mental e o físico, pertencente ao mundo externo. Bratman também vê a importância de se explicar a intenção a partir de sua relação entre dois aspectos puramente mentais (crenças e desejos) ou entre algo mental ou entre algo físico (uma crença e um ato corporal ou atividades cerebrais). No entanto, sua análise vai além do modelo desejo-crença e, também, da teoria de Searle, ao dizer que a principal característica da intenção é permitir a coordenação adequada de nossos planos.

Para Bratman, somos criaturas que planejam e formam planos para conduzir nossa conduta tendo em vista o futuro. Isso posto, diversas vezes será necessário que decidamos por um tipo $x$ ou $y$ de conduta, a despeito de ambas serem igualmente atrativas sob a perspectiva das crenças e desejos. Intenções desempenham um papel central, pois são frequentemente elementos dessas coordenações. Consequentemente, Bratman afirma que “(...) intenções são estados mentais distintos, que não podem ser reduzidos a aglomerados de desejos e crenças" (BRATMAN, 1984, p. 376).

Essa justificativa é um passo importante no reconhecimento desempenhado pela intenção em ações grupais. Antes de Searle, Bratman já reconhecia o papel desempenhado pela intenção na ontologia social. Em Bratman (1999), a intenção é incorporada numa descrição do homem como ser que planeja e adequa sua ação ao futuro e à ação alheia:

Nós somos seres que planejam. Nossa atividade intencional está tipicamente inserida em múltiplos e inter-relacionados planos de ação parciais e futuramente direcionados. Nós decidimos adiantadamente esses planos de ação, os preenchemos, os ajustamos, e os seguimos conforme o tempo passa. Assim, nós apoiamos formas complexas de organização em nossas próprias e temporalmente estendidas vidas e em nossas interações com os outros; e fazemos isso de maneiras sensíveis aos limites de nossos recursos cognitivos (BRATMAN, 1999, p. 01).

As duas faces da intenção a que Bratman faz referência no título de seu artigo dizem respeito a essas duas características das intenções: na primeira ela diz respeito à coordenação de planos e, na segunda, à ação intencional. 
Porém, para se descrever satisfatoriamente as ações coletivas de intenção compartilhada, Bratman deverá dar conta do seguinte problema exposto por Baier (1971) quando esta analisa a relação entre ação e intenção: como intencionar ações que estão fora do meu alcance realizar? Esse é o problema da segunda face da intenção, concernente à ação intencional. De acordo com Baier, só faz sentido eu intencionar aquilo que está a meu alcance. Não posso intencionar que o Sol não nasça ou, em suas palavras, "se eu não posso tocar o clavicórdio, então não posso intencionar tocá-lo" (BAIER, 1970, p. 649). Para esses casos, Baier diz que posso almejar (aim) que o sol não nasça amanhã ou tocar o clavicórdio, pois a noção de meta é mais fraca que a de intencionar e permite que eu almeje estados de coisas fora de meu alcance. Isto se relaciona com a análise de Bratman (e com qualquer autor que tenha uma teoria da ação coletiva, inclusive Searle) da seguinte maneira: participo de uma orquestra que pretende tocar a quinta sinfonia de Beethoven e meu papel é tocar, com o violino, determinada parte da sinfonia. O problema é: não posso intencionar diretamente tocar a sinfonia pois, para isto, preciso da ajuda dos outros membros da orquestra; tudo que posso fazer, ou intencionar diretamente, é tocar minha parte da sinfonia. Segundo Baier, só posso intencionar aquilo que está a meu alcance, mas tocar a sinfonia não está a meu alcance pois preciso da colaboração de outras pessoas. Como lidar com esse vácuo entre aquilo que intenciono diretamente (tocar minha parte da sinfonia) e aquilo que intenciono (tocar a sinfonia)?

A solução de Bratman é relaxar a relação entre o que se intenciona e a ação intencional. Isto é, quando, para se fazer $\mathrm{B}$, deve-se fazer $\mathrm{A}$, e $\mathrm{S}$ acredita que realizar A é um meio necessário do seu fazer $B$, então $S$ intencionalmente faz $A$, mesmo que ele não considere A como uma ação intencional. Esse relaxamento é feito a partir da formulação do conceito de potencial motivacional (motivational potential) para os casos em que eu intencionalmente faço $\mathrm{A}$ mesmo que não intencione fazer $\mathrm{A}$, mas sim B. Portanto, em suma, o que se deve levar em conta na análise de Bratman é sua descrição de intenções como auxílios coordenadores de planos complexos. Essa forma de ver a intencionalidade a restringe na medida em que impõe a unificação de nossas várias intenções, unificação necessária ao gerenciamento adequado de nossos planos. Veremos, posteriormente, como essa reflexão entrará em sua teoria da intenção e da ação compartilhada.

Essa exposição da teoria da intencionalidade de Bratman nos ajudará a compreender sua teoria da intenção compartilhada, que será observada como uma alternativa à teoria da intencionalidade coletiva de Searle.

Em "Shared Intention", Bratman expõe uma teoria da intenção compartilhada que se assemelha à teoria de Searle na recusa de se formular uma entidade mental ou um superagente que é a fusão da mente daqueles que empreendem a ação. Searle (1995), ao descrever duas formas distintas de se tratar a intencionalidade coletiva, seja através de sua redução às intenções singulares de indivíduos, ou através da criação de uma entidade mental coletiva distinta dos indivíduos que compõem a atividade grupal, acaba negando esta última devido a seu comprometimento com um certo individualismo metodológico, isto é, a crença de que somente indivíduos existem. Outra semelhança entre as duas teorias reside no fato de Bratman também acreditar que uma coincidência nos planos dos agentes da ação coletiva não é suficiente para gerar uma intenção compartilhada. Isto é: “(...) não é suficiente para uma intenção compartilhada de pintar a casa juntos que cada um intencione pintar a casa" (BRATMAN, 1993, p. 98). Intenções coincidentes não são suficientes para formar uma intenção compartilhada. Mais do que isto: intenções coincidentes nem sequer garantem que um agente saiba que o outro também vai pintar a casa. No entanto, essa restrição leva Searle a dizer que a intencionalidade coletiva é constituída por uma forma primitiva "Nós Intencionamos", que não consiste na soma de intenções individuais da forma "Eu intenciono". A restrição de Bratman é, então, semelhante à de Searle? Pode-se 
dizer que não. Nesse momento inicial, Bratman se compromete com uma restrição mais fraca que Searle, que chamaremos de "Restrição da coincidência":

Se A e B pretendem fazer $x$ no momento $t$, a crença coincidente $C$ que ambos compartilham em $t$ não é suficiente, por si só, para que A e B façam $x$. Essa restrição é mais fraca que a imposição de Searle sobre a forma primitiva da intencionalidade coletiva:

Imposição da forma primitiva searleana: Dado uma ação coletiva $x$, temos $\forall \mathrm{x}(\mathrm{Mx} \rightarrow$ Tx), onde M: membro de um coletivo; T: tem a forma primitiva "Nós Intencionamos"; e, traduzindo: Para $x$, se $x$ for um membro de um coletivo, então $x$ tem a forma primitiva "Nós Intencionamos".

A primeira suposição de Bratman sobre a intenção compartilhada diz respeito à sua compreensão: devemos analisá-la como “(...) um estado de coisas que consiste primariamente de atitudes apropriadas de cada participante individual e suas interrelações" (BRATMAN, 1993, p. 99). Junto com sua natureza, dever-se-á ver qual papel ela desempenha em nossas vidas. Desse modo, Bratman chega a três aspectos:

1. A intenção compartilhada como coordenadora das minhas atividades com as suas. Esse aspecto refere-se às ações intencionais;

2. Ela coordenará nossas ações permitindo que minha parte do plano esteja de acordo com sua parte no plano;

3. Ela providenciará um modo de estruturar barganhas ou organizar preferências conflituosas.

No final, o objetivo será realizar $x$ (pintar uma casa, no caso de Bratman).

Descritos esses aspectos, partimos para uma questão colocada por Bratman que nos permitirá analisar mais a fundo a forma como ele concebe a natureza da intenção compartilhada:

Existem atitudes de cada agente individual - atitudes que têm o conteúdo apropriado e estão inter-relacionadas de forma apropriada - cujo complexo que consiste dessas atitudes irá, se funcionar apropriadamente, realizar o trabalho da intenção compartilhada? Podemos descrever um complexo apropriado do qual o funcionamento adequado produzirá ação coordenada e planejamento, além da estrutura adequada para a barganha característica de intenções compartilhadas? Se sim, teremos razões para identificar intenção compartilhada com este complexo. (BRATMAN, 1993, p. 100)

Portanto, seremos levados a uma investigação semelhante àquela empreendida por Searle acerca da natureza da intencionalidade coletiva. Os complexos analisados - e criticados - por Searle tinham como princípios, em seus termos, metodologias capitalistas (ou individualistas) e socialistas (ou coletivistas) (SEARLE, 1990). Deve-se ressaltar que esses não passam de termos que Searle achou conveniente utilizar; eles não dizem respeito ao capitalismo e socialismo em si. A metodologia capitalista compreendia a intencionalidade coletiva como a soma de ação intencional e crenças sobre as ações intencionais dos outros indivíduos do grupo. O problema dessa análise é o seguinte: mesmo com a adição de crenças sobre a ação alheia, ela é incapaz de nos dar um quadro claro acerca da cooperação, isto é, ação intencional e crenças alheias não são suficientes para gerar cooperação. Outro problema é o do círculo vicioso: eu tenho uma crença de que você tem uma crença de que eu tenho uma crença de que você tenha uma crença, ad infinitum. A solução coletivista é rejeitada, por sua vez, por ignorar as contribuições que indivíduos fazem com suas ações individuais a uma ação grupal. No final, essa digressão à teoria de Searle nos permitirá ver se Bratman cai em algum desses problemas. Nesse sentido, a relação entre a ação individual e seu papel na coordenação do plano terá um papel central.

Já a estratégia de Bratman é compreender a intenção compartilhada como uma rede que consiste em cada uma de nossas atitudes relevantes e suas inter-relações. Em suas 
palavras, ela é um “(...) estado de coisas (state of affairs) que consiste primariamente em atitudes (nenhuma das quais são elas mesmas intenções compartilhadas) dos participantes e as inter-relações entre estas atitudes" (BRATMAN, 1993, pp. 107-108). Ou seja, uma intenção compartilhada para realizar J irá incluir as ações dos membros da ação grupal e suas interligações. À medida que nossas atitudes dirão respeito a J, ou tivermos a intenção de fazer J, nossas ações favorecerão a coordenação, pois são as ações coordenativas que nos ajudarão a conseguir J. Uma intenção compartilhada não é uma fusão de mentes individuais ou sequer um tipo de intenção presente nas mentes individuais dos participantes. Todavia, a teoria de Bratman acerca da Atividade Cooperativa Compartilhada (Shared Cooperative Activity (SCA)) difere da de Searle num ponto de extrema importância: sua teoria é individualista, pois reduz a SCA às intenções dos indivíduos presentes na atividade compartilhada: "Esta formulação da SCA é espiritualmente individualista; pois tenta entender o que há de distintivo acerca da SCA em termos das atitudes e ações dos indivíduos envolvidos" (BRATMAN, 1999, p. 108). Em suma, Bratman acredita que uma redução é plenamente possível, ao contrário de Searle.

Junto com a circularidade, Bratman se depara com outro problema: se nas atitudes dos participantes individuais que constituem uma intenção compartilhada estarão incluídas, também, suas intenções, como resolver o problema que o agente não realize a ação coletiva J, mas sim sua própria ação? Com Searle foi visto uma dificuldade semelhante, que podemos descrever da seguinte maneira:

Premissa geral: Individualismo metodológico - na sociedade não há nada mais que indivíduos com suas intenções individuais;

Premissa específica 1: Indivíduos, com suas intenções individuais, agem coletivamente;

Premissa específica 2: A forma lógica das intenções individuais não é capaz de explicar, sem contradições, a ação coletiva;

Conclusão: Indivíduos agem coletivamente com outro tipo de intencionalidade, com forma distinta da intencionalidade individual.

No entanto, como se viu, indivíduos só podem agir coletivamente a partir de suas ações individuais. Aqui, a questão de Bratman se aplica: "Como o conceito de ação em conjunto penetra nas intenções dos indivíduos?" (BRATMAN, 1993, p. 101). Bratman, inicialmente, distingue duas alternativas: na primeira, utilizaremos a noção referente ao meu fazer minha parte na nossa ação conjunta J, assim, mesmo que eu não intencione ou faça nosso J, ele é algo que eu quero. Na segunda, faz-se referência ao fato de nós não falarmos somente de intenções para (to), mas também de intenções que (that), intenções que eu ou alguém faça algo, como ligar o carro, limpar o quarto, estude no momento $t$, etc. Desse modo, Bratman infere que podemos falar de intenções que nós J. Qual dessas estratégias é mais apropriada?

Para entender qual dessas estratégias será adotada, vejamos quais são as exigências de Bratman:

Exigência 1: Eu não realizo J diretamente, mas contribuo com sua efetivação, de modo que eu esteja J-ando (J-ing) mesmo que não intencione J diretamente;

Exigência 2: Não se deve fazer referência a algum tipo novo de atitude;

Exigência 3: Devo intencionar aquilo que está sob meu controle intencionar;

Exigência 4: Minhas ações devem ser consistentes e coerentes com nosso ou o meu plano.

Outras exigências podem ser aduzidas, mas focaremos somente nessas. Novamente: qual das alternativas responde adequadamente a essas exigências? Bratman afirma 
que a segunda estratégia é a mais apropriada. Vejamos exigência por exigência como a segunda alternativa responde a elas:

Exigência 1: Aqui, de fato a ação intencional não é J, mesmo que eu o intencione. Minha ação intencional é A (minha ação no momento), porém, como visto em seu artigo "Two Faces of Intention", posso intencionar J, a consequência de minha ação, apesar de a ação intencional ser A. Em vista disso, contribuo com J a partir de A, portanto, a primeira exigência é satisfeita.

Exigência 2: Não há aqui, como em Searle, a utilização de uma intenção com uma forma primitiva da intencionalidade individual. A noção utilizada continua sendo a de intenção, mas uma intenção que tem em seu conteúdo a atividade conjunta $\mathrm{J}$, nosso J-endo (J-ing).

Exigência 3: Uma ação coletiva está fora do meu alcance. Para realizá-la, preciso da cooperação de outros agentes com suas intenções compartilhadas, dispostos a adaptar suas ações com a minha. Consequentemente, realizar a ação intencional J (a ação coletiva) está além das minhas capacidades. No entanto, como se já viu, eu contribuo com nosso J a partir da influência que minha ação A exerce no plano geral e nas ações alheias. Não realizo o que está fora de meu controle.

Exigência 4: Minha ação A faz parte do nosso intencionar J. Logo, meu A se harmoniza com nosso J e as intenções alheias contidas nele.

Todavia, podemos agora adicionar uma exigência geral, mais ampla que as anteriores:

Exigência 5: A alternativa selecionada deve explicar como a intenção compartilhada contribui com o aspecto da coordenação relativo ao direcionamento das atividades em direção do objetivo final, seja através da coordenação ou da barganha.

Com as exigências satisfeitas, Bratman anuncia que sua formulação da intenção compartilhada para J “(...) irá apelar à sua e à minha intenção que nós J" (Idem, p. 102). Entretanto, deve-se notar que Bratman não afirma que a segunda estratégia é a única possível ou que a primeira está fadada ao fracasso, somente que a segunda é mais frutífera. Devemos ver como a quinta exigência, recentemente adicionada, constrange a segunda alternativa. Nesse momento, vale a pena, antes de partir para a posição defendida por Bratman, analisar alguns dos problemas encontrados por ele em outras visões. Vejamos a primeira tentativa de atender à exigência 5:

Primeira visão: Nós intencionamos J se e somente se eu intencione J e você intencione J (Idem, p. 103).

Qual é, afinal, o problema com ela? Aqui, Searle pode auxiliar-nos na identificação do problema, pois seu diagnóstico é semelhante ao de Bratman. Fazer apelo às intenções e crenças alheias não é, como vimos, suficiente para engendrar uma intencionalidade coletiva. Dos dois problemas selecionados por Searle, um deles é compartilhado por Bratman: a formulação da primeira ignora a cooperação, pois posso intencionar que nós façamos J mesmo que eu não saiba que você também intenciona J. Isto é, a primeira visão deixa um vácuo de extrema importância. Se não sei que você intenciona J, você também pode não saber que eu intencione J, assim, nosso J é produto de mera coincidência desprovida de coordenação. Portanto, essa visão deve ser abandonada. Para Bratman, na intenção compartilhada as atitudes que um indivíduo tem devem estar expostas ao público.

Antes de vermos as outras visões, retornemos à definição que Bratman faz da intenção compartilhada: ela não é uma intenção presente numa fusão de mentes nem sequer presente nas mentes individuais dos participantes. Ela é, na realidade, um estado de coisas que consiste nas atitudes dos participantes e suas inter-relações, atitudes essas que não fazem referência à própria noção de intenção compartilhada, 
para que se evite a circularidade. Com isto em mente, deve-se procurar por uma visão que atenda a esta definição, não sendo circular nem que exclua a cooperação e a barganha.

Ademais, uma visão adequada de intenção compartilhada deve satisfazer os seguintes requisitos: o requisito do conhecimento mútuo, isto é, que eu intencione que nós J “(...) em parte por causa da sua intenção relevante” (Idem, p. 104); e aquilo que Bratman chama de "coordenação interpessoal de nossos planos" (Idem, p. 105), ou seja, para uma coordenação completa, precisamos incluir os subplanos relevantes contidos nas intenções (incluir todos os subplanos é impossível e, em casos de competição, indesejável, pois não desejo que meu adversário saiba o que vou fazer), de forma que esses subplanos também não sejam subvertidos.

Conforme a satisfação dessas exigências, temos a quarta visão (a segunda e terceira satisfazem, respectivamente, os requisitos de conhecimento mútuo e de adição de subplanos e, por motivos de espaço, não as apresentamos aqui):

Quarta visão: Nós intencionamos J se e somente se

1. (a) Eu intenciono que nós façamos J e (b) você intencione que nós façamos J.

2. Eu intenciono que nós façamos J de acordo com e por causa de 1a, 1b, e subplanos misturados de 1a e 1b; você intenciona que nós façamos J de acordo com e por causa de $1 \mathrm{a}, 1 \mathrm{~b}$, e subplanos misturados de $1 \mathrm{a}$ e $1 \mathrm{~b}$.

3. 1 e 2 são conhecimento comum entre nós (Idem, p. 106).

Dessa maneira, na quarta visão, temos o fato de eu ou você intencionarmos J à medida que interconectamos nossos subplanos, mas não todos. Ela é fraca o suficiente para permitir que duas pessoas intencionem algo mesmo que a atividade não seja totalmente cooperativa, ou que as pessoas concernentes não ajam por motivos ou intenções semelhantes. Por exemplo, vejamos o seguinte exemplo: uma orquestra tocará a 5 a sinfonia de Beethoven. Como em toda orquestra, cada um deve contribuir com sua respectiva parte, que deve ser distinta da parte de outras pessoas, ao mesmo tempo que todos tenham como objetivo final tocar a sinfonia. A orquestra fará um bom trabalho se cada membro realizar apropriadamente sua função de acordo com a função de outro membro, fazendo com que o todo seja harmônico. Isto é, cada membro deve planejar sua ação de acordo com a ação de outro membro. A visão quatro daria conta de explicar tal exemplo sem cairmos em contradições ou absurdos?

Vejamos passo a passo: No primeiro item, devemos ter um inter-relacionamento de intenções: eu intenciono que nós toquemos a sinfonia e você intencione que nós a toquemos também. Após isto, o segundo item impedirá um possível caso em que obrigo algum membro a tocar bem sua parte na sinfonia, pois, do contrário, lhe causarei algum mal. Você deve intencionar tocar a sinfonia devido ao meu intencionar tocar a sinfonia e de todo outro membro da orquestra, e temos os subplanos mais relevantes misturados. Mesmo assim, como diz Bratman, a visão quatro permite uma intenção compartilhada mesmo que as razões para que cada agente aja sejam distintas. Um membro pode tocar aquela orquestra à procura do aprimoramento técnico no instrumento que ele toca; outro pode tocar por dinheiro; e outro simplesmente porque não tinha nada melhor para fazer. Nesse sentido, a quarta visão é fraca o suficiente para permitir essa exigência. Ou seja, deve-se exigir que os subplanos relevantes sejam devidamente misturados ao mesmo tempo que se permite que cada um tenha um motivo distinto para realizar a ação coletiva. Ao pintar um casa, A pode ser movido por um interesse estético; B por motivos financeiros, pois irá vender a casa; $C$ porque quer desenvolver aquilo que aprendeu na universidade de arquitetura. Descrita dessa forma, as diversas razões não entram em choque e a exigência é fraca o suficiente para permitir esses tipos de caso. 
Será útil, como último passo antes de compararmos com a teoria de Searle, sistematizarmos a visão de Bratman e considerarmos certas alterações feitas por ele posteriormente:

Princípio geral: intenção compartilhada como um estado de coisas (em Bratman (1990)), afirma que intenção compartilhada é uma "intenção do grupo" (p. 161).

Princípio específico: "Eu intenciono que nós J": Numa situação A de ação coletiva ou grupal os agentes como indivíduos têm a ideia de que podem ter a intenção que o grupo faça $\mathrm{J}$.

Temos, também, certas premissas:

1. Circularidade consiste em intenções do tipo "Intenciono que nós J" terem intenções compartilhadas;

2. Intenções do tipo "Intenciono que nós J" não contêm intenções compartilhadas; Portanto, temos como conclusão:

3. Intenções do tipo "Intenciono que nós J" não são circulares.

O objetivo de Bratman é procurar casos de atividade coletiva em que cada agente individual é neutro com relação à intenção compartilhada. De fato, há casos onde a intenção compartilhada é sumariamente ignorada. Por exemplo, no caso da orquestra, podemos ter uma situação na qual cada membro toca isoladamente, sem contato com os outros membros. Assim, cada membro não terá conhecimento da intenção alheia de tocar uma sinfonia. Mas, além disso, temos um princípio subsidiário. Chamemo-lo de "Princípio de 'nosso J', mas numa versão reduzida:

Princípio de "nosso J" reduzido:

1. Ações só intencionam diretamente aquilo que vou realizar no momento;

2. Realizar o "nosso J", ou qualquer ação coletiva, está além de intenções diretas;

3. Portanto:

4. Não posso intencionar diretamente nosso J.

Já que, como se viu, não posso intencionar diretamente nada além de minhas ações mais imediatas, realizar nosso J se mostra como uma impossibilidade. Desse modo, precisamos complementar o princípio. Vejamos os seguintes aspectos:

Princípio de "nosso J" complementado:

1. Podemos ter a intenção de fazer nosso J mesmo que seja impossível intencionar diretamente nosso J;

2. Ações individuais podem contribuir com o fazer nosso J a partir de intenções diretas;

3. Portanto:

4. Intenções diretas, a partir de ações individuais, podem contribuir com nosso J.

Pode parecer que tal princípio complementado entra em contradição com o princípio reduzido, mas deve-se ver que o que eles falam não é a mesma coisa. $\mathrm{O}$ princípio reduzido diz que não podemos intencionar diretamente nosso J. Isto é, ao pintar uma casa, só posso intencionar diretamente minha ação A no nosso J, o nosso pintar uma casa. O que não entra em contradição quando falamos que nossas intenções diretas podem contribuir com nosso J. Se tivermos a intenção de fazer J, minha intenção direta de fazer A pode contribuir com nosso J a partir do momento que A nos ajuda a alcançar J. Minha intenção direta de pintar certa parte da casa contribui com nossa intenção de pintar a casa.

De maneira resumida, o princípio reduzido diz que nós não podemos intencionar diretamente nada além daquilo que está sob nosso controle intencionar no momento. 
Intencionar diretamente J é impossível, pois em J está contida a ação de vários outros indivíduos cujas intenções não posso controlar. Já o princípio complementado diz que essa impossibilidade não impede que minhas ações contribuam com J.

Estamos aptos agora a comparar a teoria de Bratman com a de Searle. A teoria de Searle tenta responder à questão: “Como pode ser o caso que a intencionalidade com a forma "nós" (we-intentionality) pode mover corpos individuais se o conteúdo do "nós" não é o mesmo conteúdo do "Eu" que constitui o fazer sua parte do trabalho coletivo?" (SEARLE, 2010, p. 50). Searle, em sua obra mais recente, Making the social world - the structure of human civilization (2010), ao responder a essa questão, utiliza as noções de intenções prévias e intenções-em-ação.

Vejamos como ele faz isso:

1. Primeiramente, cria-se a distinção entre intenções prévias (prior intentions) e intenções-em-ação (intentions-in-action);

2. As condições de satisfação de ambos os tipos de intenção são causalmente autorreferentes;

3. Devo distinguir aquilo que posso causar individualmente e aquilo que tomo como parte da contribuição de outros agentes;

4. Conteúdos proposicionais especificam como se dão as condições de satisfação do estado intencional. Como intenções prévias e intenções-em-ação são autorreferentes, seu conteúdo proposicional só pode ser relativo àquilo que o agente pode causar;

5. Como nos casos de intencionalidade coletiva há a atuação de outros agentes, não se pode exigir de cada indivíduo que ele saiba qual a intenção do outro é. Nesses casos, "tudo que alguém precisa acreditar é que eles compartilhem os objetivos coletivos e intencionam fazer sua parte do objetivo" (Idem, p. 45).

Recuperando brevemente como intenções prévias e intenções-em-ação atuam no comportamento individual, observemos o caso simples onde alguém levanta seu braço: Intenção prévia (esta intenção prévia faz com que eu realize a ação de levantar meu braço)

Intenção-em-ação (esta intenção-em-ação causa o levantamento de meu braço)

A partir disso, posso realizar por meio de ou através de uma certa ação. Por exemplo, se formo uma concepção prévia de apertar o gatilho de uma arma, e minha intenção-em-ação causa que eu aperte o gatilho, tais intenções fazem com que eu aperte o gatilho da arma. Podemos tirar daqui dois tipos de relação: a causal por meio de (the causal by-means-of relation), relacionada ao exemplo da arma, e a constitutiva por-modo-de (the constitutive by-way-of relation), em que, por exemplo, meu levantar o braço não causa que eu vote numa assembleia, mas constitui justamente meu voto. Searle formaliza da seguinte maneira esses tipos de relação: 1) intenção-em-ação por meio de A (esta i.e.a causa A, que causa B); 2) intenção-em-ação por modo de A (esta i.e.a causa A, que constitui B).

Sem retomar passo a passo a discussão feita por Searle em "Collective Intentions and Actions", utilizemos outro exemplo dado por ele em sua atualização teórica, onde dois indivíduos tentam iniciar um carro:

Na formalização inicial, temos: intenção-em-ação coletiva B por meio do singular A (esta i.e.a causa: A carro se move, causa: B o motor dá partida)

Numa formalização posterior, em que se adiciona a cláusula da crença e explicita-se mais ainda a parte desempenhada pelo coletiva através do uso de parênteses, temos:

"Acredito (meu parceiro no coletivo também tem a intenção-em-ação da forma (i.e.a coletiva B por meio do singular A (esta i.e.a causa: A embreagem inicia, causa: B motor liga))" (Idem, p. 53). 
Lê-se, em linguagem ordinária: Eu acredito que meu parceiro no coletivo também tem intenção-em-ação da mesma forma que a minha, que é o realizar coletivo B por meio de um singular $\mathrm{A}$, em que seu papel é iniciar a embreagem, que causa $\mathrm{B}, \mathrm{o}$ motor iniciar.

Nesse momento, podemos notar uma semelhança com a teoria de Bratman: só posso causar aquilo que está em minha capacidade causar, isto é, minha ação individual. As diferenças começam a surgir quando se aborda o conteúdo referente ao coletivo. Para ver isto, peço que o leitor volte à Quarta Visão de Bratman.

A teoria de Searle entraria em conflito nos seguintes pontos: primeiro, para Searle, como vimos, não faz parte do conteúdo de minha intenção-em-ação causar algum tipo de cooperação, mas, para iniciarmos algum tipo de ação coletiva, devo acreditar que outros irão cooperar comigo. Bratman também acredita que só posso ter intençõesem-ação (em sua terminologia, "intencionar diretamente") daquilo que está a meu alcance, mas a formulação de Bratman exige algo mais forte que a mera crença na cooperação alheia. Como vimos, o próprio conceito de intenção desenvolvido por Bratman é um conceito substancialmente planejador e coordenador. Se para Searle o coletivo fica restrito a uma crença e só posso fazer aquilo que está em meu poder, e não preciso nem sequer saber qual será a cooperação alheia, Bratman coloca que minha ação deve influenciar a ação alheia a partir da coordenação e da barganha e que deve existir um conhecimento mútuo entre intenções.

Essa fraqueza da teoria de Searle fica visível quando este afirma que em "(...) atos complexos de grandes grupos ninguém sabe o que o outro está fazendo" (Idem, p. 54). Há motivos para se acreditar nisto? Num primeiro momento, sim, pois é difícil conceber um caso $C$ onde a quantidade de agentes é extremamente numerosa, e que cada um saiba o que o outro está fazendo e que eles intencionem fazer J justamente por saberem que o outro intenciona o mesmo. Mas esse problema é dissipado quando se observa aquilo que é publicamente esperado do comportamento alheio. Em suma, podemos saber qual é o comportamento esperado e publicamente verificável por outros indivíduos, ao contrário do comportamento de fato posto em prática. E é esse comportamento esperado que nós utilizamos para guiar nossas ações.

O que resta perguntar é como Searle responde ao seguinte problema: se intenções estão restritas àquilo que o agente pode efetivamente fazer, qual é o estado da intencionalidade coletiva? Já vimos que uma resposta possível é a análise de como intenções prévias e intenções-em-ação movimentam corpos individuais em ações coletivas, mas isto é tudo?

Para entender sua resposta, utilizemos novamente a "Imposição da forma primitiva Searleana": $\forall x(\mathrm{Mx} \rightarrow \mathrm{Tx})$, referida acima como "Para cada $x$, se $x$ é um membro de um coletivo, então $x$ tem a forma "Nós Intencionamos".

Essa imposição apenas nos informa sobre a forma mental contida nos agentes da ação coletiva, sendo neutra com respeito à forma que indivíduos superam suas ações individuais transformando-as em ações coletivas. Na verdade, as únicas referências feitas ao coletivo são quando, através da relação causal, agentes, com suas ações individuais, agem visando ao objetivo comum. De forma simplificada:

1. Cada agente contribui com o objetivo comum se e somente se sua ação individual deixa todos mais perto desse objetivo

Até aí, o que está envolvido é a capacidade de a intenção fazer referência àquilo que o agente pode fazer, mas, após isto, precisamos de uma crença sobre a ação alheia:

2. Crenças sobre o coletivo são necessárias para que minha ação contribua com o objetivo comum

A questão agora é ver se esses dois itens são necessários para cobrir adequadamente casos de intenção compartilhada. Tomemos o seguinte exemplo: faço parte de um time de futebol $\mathrm{C}$ que precisa urgentemente ganhar um jogo. É um jogo decisivo; 
se perdermos, o time será rebaixado e, assim, nossos salários serão diminuídos substancialmente, implicando a diminuição considerável da qualidade de vida de todos os envolvidos. Mas, em meu caso, essa possibilidade é insuportável. Sou um pai solteiro que tem três filhos para cuidar, assim, essa queda no salário significará que um deles passará fome. Para assegurar que isso não aconteça e que o time ganhe, penso num plano diabólico em que sequestro pelo menos um familiar de cada membro do time. Aviso cada membro do time sobre essa situação, ressaltando a importância da vitória para o asseguramento de suas vidas. Obviamente, não informo quem preparou esse plano diabólico. Vejamos se os dois itens colocados acima por Searle são satisfeitos, mas antes vejamos se a "Imposição da forma primitiva Searleana" é satisfeita:

1. Imposição da forma primitiva searleana, $\forall x(M x \rightarrow T x)$ : no exemplo dado, para cada $x$ que é membro do time, $x$ tem a forma primitiva "Nós Intencionamos". Isto é satisfeito mesmo em estados de coerção. Cada membro do time continua tendo a forma primitiva "Nós Intencionamos";

2. Cada agente continuará contribuindo com suas intenções individuais, e elas continuarão fazendo referência às suas próprias ações. O que poderia ocorrer de diferente é que, dada a situação, cada um - exceto eu, formulador do plano - se empenhe mais a satisfazer suas próprias intenções;

3. Cada um continuará tendo uma crença acerca do coletivo. Minhas ações individuais ainda estarão guiadas por uma crença coletiva de que cada uma irá fazer sua parte.

Cada item foi satisfeito, mas será uma conclusão repugnante dizer que esse exemplo representa um caso de ação coletiva. Para isso, a análise de Searle será mais adequada à análise lógica da forma primitiva da intencionalidade coletiva do que à formulação de uma visão rigorosa sobre a ação coletiva, eliminando casos patentemente absurdos como o dado acima. A análise de Bratman, por outro lado, faz mais do que a análise de Searle para eliminar absurdos, o que torna sua análise mais forte e de natureza distinta da de Searle. A sua natureza distinta reside no fato de Searle estar interessado em discutir uma intuição e uma pressuposição ao falar da intencionalidade coletiva: a primeira, "comportamento coletivo intencional é um fenômeno primitivo que não pode ser analisado como a soma do comportamento intencional individual" (SEARLE, 1990, p. 401); e a pressuposição, "toda intencionalidade, seja coletiva ou individual, requer um Background intencional de capacidades mentais que não são elas mesmas intencionais" (Ibidem).

A primeira intuição é de extrema importância para Searle, mas ela não é forte o suficiente para excluir os tipos de exemplos apresentados acima. Sua análise é primordialmente ontológica, pois diz algo sobre a natureza da intencionalidade coletiva. O que diz é: “A tese que nós-intenções é uma forma primitiva de intencionalidade, não reduzível a Eu-intenções mais crenças mútuas, é consistente com essas duas restrições" (Idem, p. 407). Essas duas restrições dizem respeito ao individualismo metodológico e com o fato dos indivíduos estarem radicalmente equivocados com relação à existência de outros agentes do coletivo, sendo consistente com uma situação de cérebro numa cuba. Desse modo, pode-se ver que nada aqui faz menção a uma análise mais completa da cooperação e seus pressupostos. Na verdade, Searle admite uma restrição controversa, que pode ela mesma permitir o surgimento de casos absurdos: a do cérebro na cuba. Se cérebros numa cuba podem pensar coletivamente, ou se em situações reais posso estar completamente enganado acerca do fato de estar num verdadeiro cenário de ação coletiva, o escopo da intencionalidade não fica consideravelmente reduzido?

Se Bratman não diz nada se sua análise é consistente com cérebros numa cuba, sua análise é mais forte com relação ao estarmos verdadeiramente num cenário de ação coletiva. Para facilitar, vamos criar esses dois itens: 
1. Quadro de cérebro numa cuba: posso estar engajado numa situação de ação coletiva colaborativa, pois sou um mero cérebro numa cuba sendo manipulado por cientistas que querem descobrir a natureza da ação coletiva;

2. Quadro do engano: posso estar enganado sobre estar numa situação de ação coletiva colaborativa, pois estou enganado sobre a existência de outros agentes coletivos engajados neste tipo de situação.

As duas são semelhantes? Acredito que não. Para mostrar isso, transformemos esses quadros em exemplos:

1. Quadro do cérebro numa cuba: um cientista louco pega três cérebros numa cuba e implementa em cada um deles a forma primitiva "Nós Intencionamos", fazendo com que cada um acredite que seja um membro do mesmo time de futebol A disputando o jogo no mesmo tempo $t$.

2. Quadro do engano: Somos um time de futebol que está disputando o último jogo do campeonato. Almejo a vitória de meu time pois isto vai trazer glória e um substancial aumento na minha conta bancária. No entanto, sem saber, alguns membros do time receberam propina do time adversário para que façam tudo a seu alcance para produzirem a derrota do time.

Acredito que a análise de Bratman é, no mínimo, forte o suficiente para eliminar casos de cérebro numa cuba. Na realidade, acredito que ela também é capaz de eliminar quadros de engano. Para afirmar isto, coloco: no primeiro item, penso que, apesar de o cientista ter implementado a noção "Nós Intencionamos" nos jogadores, isto não é o suficiente para produzir intencionalidade coletiva, pois tudo que se tem são indivíduos que, coincidentemente, têm a forma primitiva "Nós Intencionamos" em cada cérebro. Como dissemos anteriormente, se A e B pretendem fazer $x$ no momento $t$, a crença coincidente $C$ que ambos compartilham em $t$ não é suficiente, por si só, para que A e B façam $x$. Chamamos isto de "Restrição da coincidência" e afirmamos que ela não é suficiente para produzir casos de intencionalidade coletiva (nessa resposta, inspirei-me no artigo de Schmid (2003)). Outro problema de se permitir casos de cérebros numa cuba é que temos uma situação em que $\forall x((\mathrm{Mx} \rightarrow$ $\mathrm{Tx}) \rightarrow \mathrm{Axp}$ ), onde A: acredita que, sendo que, na realidade, é uma situação de $\sim$ p. Isto é, casos de cérebro na cuba parecem ser inúteis neste caso pois, todas vezes que se acredita que $p$, na verdade temos $\sim p$.

Já tudo que o segundo item diz é que os outros agentes que acredito estarem colaborando comigo na verdade estão simplesmente fazendo outra coisa, como estarem 1) fazendo justamente o contrário que o tipo de situação requer, ou 2) fingindo fazer algo, ou 3) fazendo de um modo que exclua minhas vontades como agente. Aqui, novamente, há motivos para se acreditar em duas coisas:

1. Todos nós temos uma forma primitiva "Nós Intencionamos". Mesmo os sabotadores têm uma forma mental "Nós Intencionamos", apesar de compartilharem essa forma mental entre eles, não entre o resto do time que almeja a vitória. Como diferenciar a primeira forma da segunda, sendo que tudo que nos interessa é apenas a forma primitiva?

2. Na análise de Bratman, excluem-se casos onde alguém faz aquilo colocado em 1), 2), e 3), pois em sua análise eu intenciono que nós façamos J porque eu intenciono que você faça $\mathrm{J}$ e você intenciona que eu faça J, e nós fazemos J a partir desse conhecimento mútuo. Ademais, nossos subplanos relevantes estarão misturados. Faz parte de meus subplanos que não tenha nenhum sabotador no time, ou seja, se você é um, não podemos dizer que nossos subplanos relevantes se misturem, pois seus subplanos são contrários ao meu. Portanto, a análise de Bratman elimina casos de engano. 


\section{Conclusão:}

Em suma, segundo o ponto 1. posto acima, a teoria de Bratman elimina casos em que se tem a forma primitiva "Nós Intencionamos", mas essa forma primitiva relaciona-se de forma diferente com cada participante. Eliminam-se tais casos ao se colocarem exigências que os indivíduos, para que intencionem fazer J, intencionem de acordo com o conhecimento mútuo de que irão fazer J conjuntamente adicionado ao conhecimento dos subplanos relevantes. Com isto, casos como o de 1. são eliminados. Como também vimos, sua análise também não admite casos de cérebro numa cuba. No geral, por se preocupar mais com a forma primitiva mental dos casos de intenção e ação compartilhada, Bratman captura aquilo que é de maior importância para a ação coletiva: a coordenação e estruturação de planos. Bratman captura esses aspectos formulando uma teoria com fortes exigências para a ação coletiva, conforme os aspectos de sua Quarta Visão. Por outro lado, como a teoria de Searle se preocupa primordialmente com a forma primitiva mental da intencionalidade coletiva, ela acaba por permitir casos patentemente absurdos, como foi demonstrado.

Correspondência: Caio Motta. Universidade Estadual Paulista Júlio de Mesquita Filho - UNESP. Faculdade de Ciências e Letras - Câmpus de Araraquara. Rod. Araraquara-Jaú, Km 1. Machados. Araraquara - SP Brasil. CEP: 14800-901. E-mail: caiomotta36@yahoo.com.

Apoio financeiro: FAPESP.

Conflito de interesses: Nenhum.

Todos os autores leram e aprovam a versão final submetida à revista Em curso. 


\section{Bibliografia}

BAIER, A. C. Act and Intent. The Journal of Philosophy, New York, v. 67, no. 19, p. 648-658, 1970.

BRATMAN, M. E. Faces of Intention: selected essays on intention and agency. Cambridge: Cambridge University Press, 1999.

Shared Intention. Ethics, Chicago, v. 104, no. 1, p. 97-113, 1993.

Two Faces of Intention. The Philosophical Review, New York, v. 93, no. 3, p. 375-405, 1984.

SCHMID, H. B. Can brains in vats think as a team?. Philosophical Explorations, Oxfordshire, v. 6, no. 3, p. 201-217, 2003.

SEARLE, J. R. Intencionalidade. São Paulo: Martins Fontes, 2002.

Collective intentions and actions. In: MORGAN, J.; COHEN, P. R.; POLLACK, M. (Orgs.). Intentions in Communication. Cambridge: MIT Press, 1990. 2010. . Making the Social World: The Structure of Human Civilization. Oxford: Oxford University Press, Rationality in Action. Cambridge: MIT Press, 2001.

The construction of social reality. New York: The Free Press, 1995.

Recebido em: 24/Mai/2018 - Aceito em: 06/Out/2018. 